\title{
ANALISIS KEPUASAN PASIEN TERHADAP KUALITAS PELAYANAN KLINIK ARYA HUSADA MEDIKA SIDOARJO
}

\author{
Ernawati, Wara Pramesti \\ Prodi Statistika Fakultas MIPA Univ. PGRI Adi Buana Surabaya
}

\begin{abstract}
Abstrak
Kesehatan merupakan kebutuhan manusia yang utama dan prioritas yang mendasar dalam kehidupan. Penyelenggaraan pelayanan kesehatan untuk masyarakat yang tinggal di daerah di Indonesia adalah melalui pusat Kesehatan masyarakat yang bertempat di kecamatan-kecamatan sebagai pengganti keberadaan rumah sakit dan klinik-klink kesehatan yang bertanggung jawab atas kesehatan rakyat. Penelitian ini dikalukan di Klinik Arya Husada Medika Sidoarjo, yang diteliti adalah bagaimana karakteristik pasien di klinik dan Faktorfaktor apa saja yang berpengaruh terhadap kepuasan pasien di klinik. Dengan tujuan untuk mengetahui karakteristik pasien di klinik dan Mengetahui faktorfaktor apa saja yang berpengaruh terhadap kepuasan pasien di klinik. Sampel yang akan diteliti adalah pasien yang pernah mendapatkan pelayanan di Klinik Arya Husada Medika Sidoarjo tercatat pada bulan Juli sampai awal agustus 2013, Berusia 15 tahun ke atas dengan jumlah 100 pasien. Analisis statistik yang digunakan adalah Analisis deskriptif bertujuan untuk mengubah kumpulan data mentah menjadi mudah dipahami dalam bentuk informasi yang lebih ringkas, dan Structural Equation Modeling (SEM) digunakan untuk mengetahui untuk menganalisis faktor-faktor yang mempengaruhi keinginan kepuasan pasien. Karakteristik pasien dari Klinik Arya Husada Medika adalah mayoritas perempuan sebesar 57\%, Usia 36-45 Tahun 46\%, Pendidikan Terakhir Perguruan Tinggi sebesat $44 \%$, Status Pernikahan sudah Menikah sebesar 69\%, dan Jenis Pekerjaan adalah Wiraswasta / Pengusaha sebesar 38\%. Dari analisis SEM bahwa kualitas pelayanan yang memperngaruhi kepuasan pasien adalah Faktor Assurance, Responseveness, Empathy, dan Tangibles. Keempat faktor tersebut memberikan pengaruh yang signifikan terhadap kepuasan pelayanan di klinik Arya Husada Medika. Kualitas yang paling besar berepengaruh adalah faktor Tangibles. Kepuasan pelayanan dipengaruhi kualitas Responsiveness sebesar 0,05, dipengaruhi kualitas Ansurance sebesar 0,12, Empathy sebesar 0,07, dan dipengaruhi kualitas Tangibles sebesar 0,15.
\end{abstract}

Kata Kunci: Kepuasan pasien, analisis deskriptif dan analisis Structural Equation Modeling (SEM)

\section{Pendahuluan}

Kesehatan merupakan kebutuha manusia yang utama dan prioritas yang mendasar dalam kehidupan.Penyelenggaraan pelayanan kesehatan untuk masyarakat yang tinggal di daerah di Indonesia adalah melalui pusat Kesehatan masyarakat yang bertempat di kecamatan-kecamatan sebagai pengganti 
keberadaan rumah sakit dan klinik-klink kesehatan yang bertanggung jawab atas kesehatan rakyat. Penelitian ini dilakukan di klinik Arya Husada Medika Sidoarjo. Kepuasan yang dianalisa adalah kepuasan pasien terhadap kualitas pelayanan yang berkunjung di klinik Arya Husada Medika Sidoarjo, Klinik ini dilengkapi peralatan medis yang sudah standar perlengkapan rumah sakit dan juga dilengkapi dengan apotik (apotek). Klinik ini memberikan pelayanan yaitu praktek dokter umum, praktek dokter gigi, poli kecantikan, laboratorium klinik, radiologi, khitan laser dan manual, USG ABDOMEN dan USG kandungan. Analisis statistik adalah Structural Equation Modeling (SEM) digunakan untuk mengetahui untuk menganalisis faktor-faktor yang mempengaruhi keinginan kepuasan pasien. Penelitian ini diharapkan akan bermanfaat bagi klinik kesehatan untuk mengevaluasi elemen pelayanan yang perlu mendapatkan perhatian serius agar lebih meningakatkan kualitasnya.

\section{Structural Equation Modeling (SEM)}

SEM adalah teknik statistik multivariat yang merupakan kombinasi antara analisis faktor dan analisis regresi (korelasi), yang bertujuan untuk menguji hubungan-hubungan antar-variabel yang ada pada sebuah model, baik itu antar indikator dengan konstruknya, ataupun hubungan antar-konstruk (Singgih, 2012:14). Variabel laten disebut dengan konstruk atau unobserved variables. variabel laten merupakan variabel yang tidak diamati, tersusun dan diukur secara tidak langsung melalui variabel observasi atau variabel manifes yang diamati (Basuki, 2004 dalam Ichsan, 2008:9).

\subsection{Measurement Model dan Structural Model}

Measurement Model adalah bagian dari model SEM yang menggambarkan hubungan antara variabel laten dengan indikator-indikatornya. Structural Model adalah menggambar-kan hubungan antar variabel-variabel laten atau antar variabel eksogen dengan

variabel laten (Singgih, 2012:10).

\subsection{Definisi Kepuasan}

Menurut (Oliver, 1980) kepuasan adalah tingkat perasaan seseorang setelah membandingkan kinerja / hasil yang dirasakan dengan harapanya. Sedangkan (Tjiptono dan Candra, 2005 :195) mendefinisikan kepuasan sebagai upaya pemenuhan sesuatu atau membuat sesuai memadai. Dari definisi-definisi tersebut di atas dapat disimpulkan, yaitu adanya perbandingan antara harapan dan kinerja/hasil yang dirasakan pelanggan. Harapan pelanggan dibentuk dan didasarkan oleh beberapa faktor, di antaranya pengalaman berbelanja di masa lampau, opini teman dan kerabat, serta informasi dan janji-janji perusahaan dan para pesaing. Kepuasan pelanggan (Castomer Satisfaction) atau sering disebut juga dengan Total Customer Satisfaction menurut Barkely dan Saylor (1994) merupakan fokus dari proses Costomer-Driven Project Manajement (CDPM), bahkan dinyatakan pula bahwa kepuasan pelanggan adalah kualitas. 


\section{Metode Penelitian}

\subsection{Sumber Data}

Penelitian ini menggunakan sumber data primer. Teknik pengumpulan dilakukan dengan menggunakan kuesioner dan didukung dengan observasi. Objek penelitian ini adalah pasien yang berkunjung di klinik Arya Husada Medika Sidoarjo.

\subsection{Variabel dan Definisi Operasional Variabel}

Variabel dimensi kualitas pelayanan digunakan untuk mengetahui kualitas pelayanan di klinik Arya Husada Medika. Berikut adalah variabel operasional yang digunakan.

Tabel 3.1 Definisi Operasional dan Variabel Penelitian

\begin{tabular}{|c|c|c|}
\hline $\begin{array}{l}\text { Dimensi } \\
\text { Layanan }\end{array}$ & Variabel & Jenis Layanan \\
\hline \multirow{3}{*}{ Reliability } & $\mathrm{X}_{1.1}$ & $\begin{array}{l}\text { Prosedur pelayanan Puskesmas tidak berbelit- } \\
\text { belit }\end{array}$ \\
\hline & $\mathrm{X}_{1.2}$ & $\begin{array}{l}\text { Pelayanan,pemeriksaan, dan pengobatan cepat } \\
\text { dan tepat }\end{array}$ \\
\hline & $\mathrm{X}_{1.3}$ & Konsultasi dengan dokter jelas dan dimengerti \\
\hline \multirow{3}{*}{ Responseveness } & $\mathrm{X}_{2.1}$ & Pelayanan dimulai tepat waktu \\
\hline & $\mathrm{X}_{2.2}$ & $\begin{array}{l}\text { Kesigapan dokter dan petugas dalam menangani } \\
\text { keluhan pasien }\end{array}$ \\
\hline & $\mathrm{X}_{2.3}$ & Kemudahan pelayanan administr asi \\
\hline \multirow{4}{*}{ Assurance } & $\mathrm{X}_{3.1}$ & $\begin{array}{l}\text { Pasien merasa aman dan nyaman saat melakukan } \\
\text { pengobatan di puskesmas }\end{array}$ \\
\hline & $\mathrm{X} 3.2$ & Kewajaran biaya puskesmas \\
\hline & $\mathrm{X}_{3.3}$ & Kewajaran biaya obat \\
\hline & $\mathrm{X}_{3.4}$ & $\begin{array}{l}\text { Percaya dokter dan petugas bersangk utan dapat } \\
\text { menangani keluhan pasien denan tepat }\end{array}$ \\
\hline \multirow{3}{*}{ Empathy } & $\mathrm{X}_{4.1}$ & Kesediaan petugas untuk mendengarkan keluhan \\
\hline & $\mathrm{X}_{4.2}$ & $\begin{array}{l}\text { Pemberian pelayanan kepada semua pasien tanpa } \\
\text { pilih- pilih }\end{array}$ \\
\hline & $\mathrm{X}_{4.3}$ & $\begin{array}{l}\text { Kemampuan dan kemauan petugas dalam } \\
\text { berkomunikasi }\end{array}$ \\
\hline \multirow{4}{*}{ Tangibles } & $\mathrm{X} 5.1$ & Penampilan fisik gedung \\
\hline & $\mathrm{X} 5.2$ & Kebersihan, kerapihan, dan kenyamanan ruangan \\
\hline & $\mathrm{X} 5.3$ & Kebersihan toilet \\
\hline & $\mathrm{X} 5.4$ & Penampilan petugas \\
\hline
\end{tabular}

\section{Hasil dan Pembahasan}

Dari hasil penelitian tentang tentang kepuasan pasien terhadap kualitas pelayanan klinik arya husada medika sidoarjo, bisa dipengaruhi oleh faktor 
Jaminan (Anssurance), daya tanggap (Responsiveness), empathy, dan wujud nyata (Tangibles). Sehingga kepuasan pasien terhadap kualitas pelayanan klinik arya husada medika dipengaruhi oleh faktor Anssurance sebesar 0,12, dipengaruhi faktor Responsivenees sebesar 0,05, dipengaruhi faktor Emphaty sebesar0,15, dipengaruhi faktor Tangibles sebesar 0,05. Keempat faktor tersebut memberikan pengaruh yang signifikan terhadap kepuasan pasien pada pelayanan klinik arya husada medika sidoarjo. Variabel Reliability (keandalan) (X1), Responsiveness (Daya tanggap) ( 2 2), Assurance (Jaminan) (X3), Emphaty (Emphaty) (X4) dan Tangibles (Bukti langsung) (X5) valid karena valid karena rhitung $>$ rtabel.

\section{Simpulan}

Dari analisis SEM bahwa kualitas pelayanan yang memperngaruhi kepuasan pasien adalah Faktor Ansurance, Responsevenees, Empathy, dan Tangibles. Keempat faktor tersebut memberikan pengaruh yang signifikan terhadap pasien dalam kepuasan pelayanan di klinik Arya Husada Medika. Kualitas yang paling besar berepengaruh adalah faktor Tangibles. Kepuasan pelayanan dipengaruhi kualitas Responsiveness sebesar 0,05, dipeng-aruhi kualitas Ansurance sebesar 0,12, Empathy sebesar 0,07, dan dipengaruhi kualitas Tangibles sebesar 0,15 .

\section{Daftar Pustaka}

Arikunto, S. 2003. Dasar - dasar Evaluasi Pendidikan. Jakarta: Bumi Aksara Arikunto, S. 2009. Dasar - dasar evaluasi Pendididkan (Edisi Revisi). Jakarta : Bumi Aksara

Budi, Ferdi Utama. 2011. Analisisi Kepuasan Pasien Terhadap Kualitas Pelayanan Puskesmas Keputih. Jurusan Statistik FMIPA ITS Surabaya

Dimiyati dan Mudjiono. 2009. Belajar dan Pembelajaran. Jakarta : Rineka Cipta

Hari wijaya, Setyo. 2008. Structural Equation Modeling dengan Lisrel 8.8. Yogyakarta : Graha Ilmu

Hartanto Sunardi, Wara Pramesti. 2008. Statistik. University Press Adi Buana Surabaya

Hasan, Iqbal. 2004. Analisis Data Penelitian dengan Statistik. Jakarta : Bumi Aksara

J. Supranto. 1997. Pengukuran Tingkat Kepuasan Pelanggan untuk Menaikkan Pangsa Pasar. Jakarta : Rineka Cipta

J. Supranto. 2001. Pengukuran Tingkat Kepuasan Pelanggan untuk Menaikkan Pangsa Pasar. Jakarta : Rineka Cipta

Nurmansyah, Andarian Arif. 2011. Analisis Faktor yang Mempengaruhi Kepuasan Pelanggan PDAM Kota Gresik (Studi Kasus Pada Masyarkat Kecamatan Gresik). Jurusan Statistik FMIPA ITS Surabaya

Santoso, Singgih .2012. Analisis SEM Menggunakan AMOS. Jakarta : Elex Media Komputindo

Sudjana. 1996. Metode Statistika Bandung: Tarsito

Sudjana. 2005. Metode Statistika. Bndung : Tarsito 
Sufyan, Ichsan. 2008. Partisispasi Masyarakat Surabaya dalam Pembuatan Kebijakan Pemerintah Kota (Studi Kasus Kecamatan Sukolilo Surabaya). Jurusan Statistik FMIPA ITS Surabaya

Sugiyono. 2002. Statistika Untuk Penelitian. Bandung : Ikatan Penerbitan Indonesia

Slameto. 2003. Belajar dan Faktor - faktor yang Mempengaruhinya. Jakarta : Rineka Cipta

Susanto Priyo Hastono, Luknis sabri. 2006. Statistik Kesehatan. Jakarta : Raja Grafindo Persada 
